\title{
Propagação vegetativa de estaquia de azaléia arbórea (Rhododendron Thomsonii HOOK. f.)
}

\author{
Vegetative propagation by cuttings of azaléia tree \\ (Rhododendron thomsonii HOOK. f.)
}

\author{
Aurea Portes Ferriani ${ }^{1}$; Michele Fernanda Bortolini ${ }^{1}$; \\ Katia Christina Zuffellato-Ribas ${ }^{2 *}$; Henrique Soares Koehler ${ }^{3}$
}

Resumo

\begin{abstract}
Rhododendron thomsonii (Ericaceae) é uma espécie lenhosa, ornamental originária da China cujas sementes são utilizadas exclusivamente para produção de híbridos, sendo a propagação vegetativa uma ferramenta viável para a produção de mudas em larga escala. Com a finalidade de avaliar o enraizamento desta espécie para estacas colhidas na primavera (setembro/2004), foram selecionadas plantas-matrizes adultas situadas no Município de Curitiba - PR. As estacas semilenhosas foram obtidas com comprimento aproximado de $12 \mathrm{~cm}$, cortadas em bisel na parte inferior e em corte reto na parte superior, com duas folhas reduzidas à metade. $\mathrm{O}$ tratamento fitossanitário foi realizado utilizando-se imersão das estacas em hipoclorito de sódio $0,5 \%$ (10 minutos) seguida de lavagem em água corrente (5 minutos). Posteriormente as bases das estacas foram imersas em soluções alcoólicas $(50 \%)$ com diferentes concentrações de ácido indol butírico (IBA), $\left(0,1000,2000\right.$ e $\left.4000 \mathrm{mgL}^{-1}\right)$, e em talco $\left(0,1000,2000\right.$ e $\left.4000 \mathrm{mgKg}^{-1}\right)$, totalizando 8 tratamentos com 4 repetições de 9 estacas por parcela. O delineamento experimental utilizado foi o arranjo fatorial (4X2) entre as dosagens utilizadas e as formas de aplicação. As estacas foram plantadas em tubetes contendo vermiculita de granulometria média e mantidas em casa-de-vegetação climatizada por 70 dias. As avaliações compreenderam porcentagens de estacas enraizadas, com calos (sem raiz e com calos), vivas (sem raízes e sem calos) e mortas. Não houve enraizamento para estacas coletadas nesta época do ano. A análise de variância revelou que os fatores dosagens e formas de aplicação não apresentaram interação. Na comparação de médias para porcentagens de estacas vivas e mortas, os tratamentos não apresentaram diferenças estatisticamente significativas.
\end{abstract}

Palavras-chave: Rhododendron thomsonii, ácido indol butírico, estaca semilenhosa

\begin{abstract}
Rhododendron thomsonii (Ericaceae) is a chinese ornamental hardwood species. The seeds are used just for hybrids production, therefore, vegetative propagation is an appropriate way for large scale plant production. The rooting potential was evaluated in cuttings collected in spring/2004 from stock plants
\end{abstract}

1 Bióloga, Mestranda em Agronomia - Produção Vegetal, Universidade Federal do Paraná (UFPR), Curitiba - PR.

2 Bióloga, Dra., Depto. Botânica, Setor de Ciências Biológicas, Universidade Federal do Paraná (UFPR), Centro Politécnico Jardim das Américas CP: 19031 CEP: 81531-970 Curitiba - PR, Profa. Adjunta. Curitiba, PR, kazu@ufpr.br.

3 Eng. Florestal, Dr., Depto. Fitotecnia e Fitossanitarismo, Setor de Ciências Agrárias, Universidade Federal do Paraná (UFPR), Prof. Adjunto.

* Autor para correspondência. 
localized in Curitiba, Paraná. The stem cuttings were produced with $12 \mathrm{~cm}$ long, right cut upper and bevel bellow, with two half leaves and treated with sodium hypochlorite for ten minutes and current water for five minutes. The cuttings basis were dipped in IBA treatments $\left(0,1000,2000,4000 \mathrm{mgL}^{-1}\right)$ in alcoholic solutions and talc $\left(0,1000,2000,4000 \mathrm{mgKg}^{-1}\right)$, totalling eight treatments with four replications of nine cuttings. Mean separation were made using a pair wise design (4X2) in a association between dosage and application ways. The cuttings were planted in vermiculite medium and maintained in greenhouse for 70 days. The evaluation included percentage of rooting, callus cuttings (without root with callus), alive and dead cuttings. No rooting was verified in cuttings collected in this season. The variance analysis showed no interactions between dosage and application ways.

Key words: Rhododendron tomsonii, indolebutyric acid, semihardwood cutting

\section{Introdução}

A propagação das plantas ornamentais vem se difundindo com o objetivo de melhorar a qualidade de vida da população, que cada vez mais investe no paisagismo dos ambientes, gerando o crescente interesse pelas técnicas particulares de produção dessas plantas (ANGELIS-NETO; ANGELIS, 1999; CUQUEL; GRANJA; MINAMI, 1992).

Rodhodendron thomsonii Hook. f. (Ericaceae), popularmente conhecida como azaléia arbórea, é um arbusto lenhoso, ramificado, originário da China e Tibete, com 2-5m de altura. Possui folhas elípticas longas, coriáceas, aglomeradas na extremidade e permanentes, por isso o nome "Rhododendron", plantas que não perdem as folhas no inverno. Apresenta inflorescências terminais, com flores numerosas e grandes de coloração vermelha ou rosa, destacando-se pelo efeito ornamental nas estações do outono e inverno. Pode ser cultivada em pleno sol de preferência em regiões frias, onde se desenvolve e floresce melhor (LORENZI; HERMES, 1999). Suas sementes são utilizadas exclusivamente na produção de híbridos, sendo a propagação vegetativa a forma de produção de mudas mais difundida.

Para propagar vegetativamente, basta destacar qualquer parte da planta - matriz obtendo-se a regeneração da parte ou partes que estão faltando, a fim de formar uma planta nova e completa (JANICK, 1966). A estaquia, uma das formas de clonagem vegetal, possibilita uma uniformidade das plantas, um grande número de mudas produzidas a partir de apenas uma planta matriz, além da antecipação do período de florescimento, já que se tem a redução do período juvenil (HARTMANN et al., 2002).

Tratar as estacas com auxinas sintéticas pode estimular a emissão de raízes em espécies cujo enraizamento não é tão alto em condições naturais, mas tem também como objetivos aumentar a produção de mudas em menor espaço de tempo, com maior número e maior vigor das raízes, além de aumentar a uniformidade do enraizamento (BOLIANI; SAMPAIO, 1998). Estas características acabam por diminuir o tempo de permanência da estaca no leito de enraizamento (FERREIRA et al., 2001) e de formação das mudas (ALVARENGA; CARVALHO, 1983). Outro fator importante é o de que as mudas com melhor sistema radicial terão maiores chances de sobrevivência proporcionando melhor ancoragem quando transplantadas para vaso ou campo (REIS et al., 2000). O ácido indol butírico (IBA), uma auxina sintética, é mais estável e menos solúvel que a auxina endógena ácido indol acético (IAA), sendo considerado um dos melhores estimuladores do enraizamento.

No entanto não são encontrados trabalhos na literatura que relatem o sucesso ou fracasso do enraizamento de estacas de azaléia arbórea. Assim o presente trabalho teve como objetivo verificar a resposta da estaquia de Rhododendron thomsonii Hook. f., utilizando diferentes formas de aplicação e concentrações de ácido indol butírico . 


\section{Material e Métodos}

Foram utilizadas estacas caulinares semilenhosas de plantas matrizes adultas de Rhododendron thomsonii, coletadas no Município de Curitiba - PR, na primavera (setembro/2004).

As estacas foram obtidas com um corte em bisel abaixo da última gema basal e corte reto acima da última gema apical, deixando-as com um comprimento aproximado de $12 \mathrm{~cm}$, sendo mantidas duas folhas na porção apical com sua área reduzida à metade. Para a desinfestação, as estacas foram imersas em hipoclorito de sódio a $0,5 \%$ por dez minutos, com posterior lavagem em água corrente por cinco minutos.

As bases das estacas foram tratadas com diferentes concentrações de ácido indol butírico (IBA) aplicadas sob a forma de talco e solução alcoólica (50\%), por dez segundos de imersão conforme os seguintes tratamentos (T): $\mathrm{T}_{1}\left(0 \mathrm{mgKg}^{-1} \mathrm{IBA}\right) ; \mathrm{T}_{2}\left(1000 \mathrm{mgKg}^{-1} \mathrm{IBA}\right) ; \mathrm{T}_{3}$ (2000 $\mathrm{mgKg}^{-1}$ IBA); $\mathrm{T}_{4}\left(4000 \mathrm{mgKg}^{-1} \mathrm{IBA}\right) ; \mathrm{T}_{5}(0$ $\left.\mathrm{mgL}^{-1} \mathrm{IBA}\right) ; \mathrm{T}_{6}\left(1000 \mathrm{mgL}^{-1} \mathrm{IBA}\right) ; \mathrm{T}_{7}\left(2000 \mathrm{mgL}^{-1}\right.$ IBA); $\mathrm{T}_{8}\left(4000 \mathrm{mgL}^{-1} \mathrm{IBA}\right)$.

O plantio foi realizado em tubetes de polipropileno com $53 \mathrm{~cm}^{3}$, contendo vermiculita de granulometria média como substrato, em casa-de-vegetação climatizada ( $80 \%$ UR) do Setor de Ciências Biológicas, da UFPR, em Curitiba PR. Depois de 70 dias foram analisadas as seguintes variáveis: porcentagem de estacas enraizadas, número de raízes por estaca, comprimento das 3 maiores raízes por estaca, porcentagem de estacas vivas (sem raízes e sem calos), porcentagem de estacas com calos (sem raízes e com calos) e porcentagem de estacas mortas.

O delineamento foi inteiramente casualizado com 8 tratamentos, aplicados em 4 repetições de 9 estacas por parcela, sendo composto de um arranjo fatorial de 4 diferentes concentrações e 2 formas de aplicação, totalizando 288 estacas.

\section{Resultados e Discussão}

De acordo com os resultados obtidos, nenhum dos tratamentos utilizados favoreceu a indução radicial em estacas de Rhododendron thomsonii, o que justifica o fato da variável porcentagem de enraizamento não ser apresentada.

Devido ao número reduzido de estacas que apresentaram formação de calos $(3,82 \%)$, esta variável não foi considerada na análise estatística. Dessa maneira, foram analisadas as porcentagens de estacas vivas (sem calos e sem raízes) e mortas.

Os resultados estatísticos apresentados referemse à análise de variância e teste de Tukey para comparação das médias. A análise de variância (Tabela 1) revelou que a interação dos fatores concentração e forma de aplicação não foi estatisticamente significativa para ambas as variáveis, indicando que os fatores são independentes.

Tabela 1. Análise de variância para a porcentagem de estacas de Rhododendron thomsonii vivas e mortas (setembro 2004).

\begin{tabular}{l|c|c|c}
\hline \multirow{2}{*}{ Fator de Variação } & \multirow{2}{*}{ G.L. } & \multicolumn{2}{|c}{ Quadrado Médio } \\
\cline { 3 - 4 } & & Vivas & Mortas \\
\hline Concentração & 3 & $72,016^{\mathrm{ns}}$ & $44,965^{\mathrm{ns}}$ \\
Forma de aplicação & 1 & $138,889^{\mathrm{ns}}$ & $34,771^{\mathrm{ns}}$ \\
Concentração x Forma de aplicação & 3 & $46,296^{\mathrm{ns}}$ & $24,492^{\mathrm{ns}}$ \\
Erro & 24 & 234,053 & 173,244 \\
Coeficiente de Variação (\%) & & 18,67 & 88,14 \\
Teste de Bartlett $\left(\chi^{2}\right)$ & & $22,05^{\mathrm{ns}}$ & $41,65^{\mathrm{ns}}$ \\
\hline
\end{tabular}

${ }^{\text {ns }}$ não significativo a $5 \%$ de probabilidade 
Considerando as concentrações de ácido indol butírico utilizadas nos tratamentos, estas não revelaram diferenças estatisticamente significativas para as variáveis em questão. A Tabela 2 apresenta a comparação das médias obtidas para as variáveis porcentagem de estacas vivas e mortas, nas respectivas concentrações, de acordo com o veículo utilizado (solução ou talco).

Tabela 2. Médias para as diferentes concentrações aplicadas de ácido indol butirico (IBA), em estacas de Rhododendron thomsonii quanto à porcentagem de estacas vivas (sem raízes e sem calos), e porcentagem de estacas mortas após 70 dias do início do experimento.

\begin{tabular}{c|c|c}
\hline $\begin{array}{c}\text { Concentrações } \\
\left(\mathbf{m g K g}^{-1} \text { ou } \mathbf{~ m g L}^{-\mathbf{1}}\right)\end{array}$ & $\begin{array}{c}\text { Estacas vivas } \\
(\mathbf{\%})\end{array}$ & $\begin{array}{c}\text { Estacas mortas } \\
(\mathbf{\%})\end{array}$ \\
\hline 0 & $81,11 \mathrm{a}$ & $13,06 \mathrm{a}$ \\
1000 & $86,11 \mathrm{a}$ & $12,50 \mathrm{a}$ \\
2000 & $80,56 \mathrm{a}$ & $18,06 \mathrm{a}$ \\
4000 & $79,17 \mathrm{a}$ & $15,28 \mathrm{a}$ \\
Média & 81,74 & 12,25 \\
C.V. (\%) & 18,67 & 88,14 \\
\hline
\end{tabular}

Médias seguidas da mesma letra na coluna não diferem estatisticamente entre si pelo teste de Tukey no nível de $5 \%$ de probabilidade

Os resultados indicaram baixas porcentagens de estacas mortas $(12,25 \%)$ e altas porcentagens de estacas vivas $(81,74 \%)$ sugerindo que possivelmente a manutenção de tais estacas no leito de enraizamento por um período maior de tempo poderia induzir a formação de raízes nas mesmas, uma vez que neste experimento foi adotado o período de 70 dias conforme protocolo utilizado para outras espécies arbustivas e lenhosas. Entretanto, Adams e Roberts (1967), trabalhando com as cultivares "Cynthia", "Pink Pearl" e "Britannica" do gênero Rhododendron mantiveram estacas caulinares no leito de enraizamento por 100 dias. Para Rhododendron maximum a permanência das estacas foi de 135 dias (WILLIAMS; BILDERBACK, 1980).
Jordanov (apud STANKOVA; PANETSOS, 1997) destaca que as espécies apresentam períodos variáveis para indução de enraizamento, como é o caso das estacas de Cupressus sempervirens que foram acompanhadas por 220 dias. RIBAS (1993) verificou que o tempo necessário para se estabelecer o sistema radicial em estacas de Macadamia integrifolia foi de 120 dias após a instalação do experimento.

Com relação às formas de aplicação (Tabela 3) também não houve diferença estatisticamente significativa para as variáveis analisadas. No entanto, comparando-se os resultados numéricos, possivelmente as estacas da espécie estudada apresentam maior resposta aos tratamentos aplicados sob a forma de solução $(84,03 \%$ de sobrevivência).

Tabela 3. Médias para as diferentes formas de aplicação de ácido indol butírico (IBA), para estacas de Rhododendron thomsonii quanto à porcentagem de estacas vivas (sem raízes e sem calos) e porcentagem de estacas mortas após 70 dias do início do experimento.

\begin{tabular}{c|c|c}
\hline Modo de aplicação & $\begin{array}{c}\text { Estacas vivas } \\
\text { (\%) }\end{array}$ & $\begin{array}{c}\text { Estacas mortas } \\
\text { (\%) }\end{array}$ \\
\hline Talco & $79,86 \mathrm{a}$ & $15,98 \mathrm{a}$ \\
Solução & $84,03 \mathrm{a}$ & $13,89 \mathrm{a}$ \\
Média & 81,94 & 14,93 \\
\hline
\end{tabular}

Médias seguidas da mesma letra na coluna não diferem estatisticamente entre si pelo teste de Tukey no nível de $5 \%$ de probabilidade 
Paes (2002) observou variação na resposta entre cultivares de kiwi (Actinidia deliciosa) às formas de aplicação do fitorregulador. As cultivares Bruno e Monty apresentaram maior porcentagem de enraizamento quando tratadas com talco, enquanto a cultivar Abbott respondeu melhor à solução. Estacas de pau-de-leite (Sapium glandulatum) também enraizaram em maior porcentagem quando o tratamento foi em solução, na comparação com a forma de talco (FERRI, 1997).

No entanto, há outros trabalhos desenvolvidos com azaléia que apresentam resultados satisfatórios quanto a porcentagem de enraizamento com a utilização de talco. Davis e Potter (1985), utilizando $3000 \mathrm{mgKg}^{-1}$ de IBA obtiveram $100 \%$ de enraizamento para Rhododendron catawbiense. Para a cultivar "Anna Rose Whitney" 97\% das estacas enraizaram após 80 dias no leito de enraizamento, com a utilização de $8000 \mathrm{mgKg}^{-1}$ de IBA (FRENCH, 1990).

O uso de NAA (ácido naftaleno acético) ou da combinação deste com IBA já foram testadas com resultados satisfatórios quanto ao enraizamento de estacas caulinares de azaléia (ADAMS; ROBERTS, 1967; NAKAMURA; MATSUI; HARADA, 1978).

Todas as estacas desenvolveram brotações, indicando um possível motivo da ausência do enraizamento, uma vez que poderia haver competição da brotação pelos carboidratos na estaca que estariam disponíveis para a formação de raízes. Um outro fator a ser considerado quando ocorre brotação em estacas é o aumento da transpiração e conseqüente perda de umidade destas antes que estejam aptas a formar raízes, conforme observado por Rauter (apud STANKOVA; PANETSOS, 1997). A relação de redirecionamento de energia (fonte dreno), também foi observada por Adams e Roberts (1987), quando o desenvolvimento de gemas em estacas de três cultivares do gênero Rhododendron inibiu a iniciação radicial.

Outro motivo para o não enraizamento da espécie pode ser a ausência de co-fatores do enraizamento, substâncias endógenas como carboidratos, compostos nitrogenados e vitaminas que são capazes de atuar sinergicamente com as auxinas, como promotores ou inibidores deste processo. Neste caso, só a aplicação de auxinas exógenas não é eficaz para o processo de enraizamento (HARTMANN et al., 2002).

Além das concentrações ideais de auxinas e de co-fatores, o sucesso do enraizamento depende de características anatômicas das espécies. A ausência da emissão dos primórdios radiciais, em alguns casos é devido à presença de fibras e esclereides no floema primário do caule da estaca, formando um anel contínuo na região cortical do caule, características presentes na grande maioria de estacas coletadas de plantas adultas (WHITE; LOVELL, 1984).

A utilização de pequenas incisões na base das estacas precedendo o tratamento com fitorreguladores tende a eliminar a influência de barreiras anatômicas, facilitando a emergência das raízes. Tais práticas denominadas "injúrias" são citadas por Davis e Potter (1985) e French (1990), como procedimento na estaquia de azaléia.

As diferentes estações do ano em que as estacas são coletadas apresentam efeito sobre o enraizamento, parecendo estar relacionadas ao nível endógeno de auxina, carboidratos e proteínas, que são importantes no decorrer do processo e que variam para cada espécie. O trabalho de Iritani et al. (apud ZUFFFELATO-RIBAS; RODRIGUES, 2001), comprova essa relação, quando estacas de erva-mate enraizaram $75 \%$ no verão, e no inverno apenas 26,78\%. Estacas de diferentes cultivares de kiwi (Acitinidia deliciosa) também apresentaram variações na resposta do enraizamento, sendo os maiores índices no inverno e no verão (PAES, 2002).

Para promover o enraizamento de Rodhodendron thomsonii Hook. f., que neste caso não ocorreu, o material utilizado poderia ser rejuvenescido através de poda drástica, conforme trabalho realizado com estacas provindas de brotações jovens de touça ou da parte aérea de plantas jovens de corticeira-dobanhado (Erythrina crista-galli L.), que 
apresentaram maior enraizamento do que estacas coletadas de plantas adultas (CARPANEZZI; TAVARES; SOUSA, 2001). O enraizamento poderia ser obtido também com a aplicação de citocininas ou herbicida; propagação seriada via enxertia; propagação seriada via estaquia, além de técnicas na micropropagação (HIGASHI; SILVEIRA; GONÇALVES, 2000; HARTMANN et al., 2002). A obtenção de mini-estacas provenientes de subcultivos aumentou significativamente o potencial de enraizamento para híbridos de Rhododendron yakushimanum, conforme verificado por Marks (1991).

Como alternativas para indução do enraizamento poderia ser utilizado o anelamento nos ramos antes de serem removidos da planta matriz, bloqueando assim a translocação descendente de carboidratos, hormônios e outros fatores promotores. Outra técnica denominada estiolamento, que diminui a foto-oxidação das auxinas, acumulando-as nos ramos e também diminuindo a quantidade de lignina nas paredes celulares, facilitando a saída das raízes através dos tecidos (CASTRO; KERSTEN, 1996; HARTMANN et al., 2002). Hansen e Potter (1997), aplicando a técnica de estiolamento em plantas matrizes de cultivares de Rhododendron, verificaram aumento na porcentagem de enraizamento e número de raízes por estaca.

\section{Conclusão}

Nas condições em que foi desenvolvido este experimento, as estacas de Rhododendron thomsonii Hook. f., não apresentaram resposta ao enraizamento, sendo necessários outros estudos abordando diferentes épocas de coleta das estacas, outros tratamentos, além de análises químicas e morfológicas para detectar possíveis causas da ausência da indução radicial.

\section{Referências}

ADAMS, D. B.; ROBERTS, A. N. A morphological time scale for predicting rooting potencial in Rhododendron cuttings. American Society for Horticultural Science, Alexandria, v.91, p.753-76. 1967

ALVARENGA, L. R.; CARVALHO, V. D. Uso de substâncias promotoras de enraizamento de estacas frutíferas. Informe Agropecuário, Belo Horizonte, v.9, n.101, p.47-55, 1983.

ANGELIS NETO, G.; ANGELIS, B. L. D. Plantas ornamentais: do paisagismo a outras aplicações. Revista Brasileira Horticultura Ornamental, Campinas, v.5, n.1, p.12-19, 1999.

BOLIANI, A. C.; SAMPAIO, V. R. Efeitos do estiolamento basal e do uso do ácido indol-butírico no enraizamento de estacas de nespereira (Eriobotrya japonica Lindley). Cultura Agronômica, Ilha Solteira, v.7, n.1, p.51-63,1998.

CARPANEZZI, A. A.; TAVARES, F. R.; SOUSA, V. A. Estaquia de Corticeira-do-banhado (Erythrina cristagalli L.). Colombo: Embrapa, 2001. (Comunicado Técnico)

CASTRO, A. M.; KERSTEN, E. Influência do anelamento e estiolamento de ramos na propagação de laranjeira valência (Citrus sinensis Osbeck) através de estacas. Scientia Agrícola, Piracicaba, v.53, n.2/3, p.199-203, 1996.

CUQUEL, F. L.; GRANJA, N. P.; MINAMI, K. Avaliação do enraizamento de estacas de crisântemo (Chrysanthemum morifolium L.) cv. White reagen 606 tratadas com ácido indol butírico (IBA). Scientia Agrícola, Piracicaba, v.49, n.1, p.15-22, 1992.

DAVIS, T. D.; POTTER, J. R. Carbohydrates, water potential, and subsequent rooting of stored Rhododendron cuttings. HortScience, Alexandria, v.20, n.2, p.292-293. 1985

FERREIRA, B. G. A.; ZUFFELLATO - RIBAS, K. C.; CARPANEZZI, A. A.; TAVARES, F. R; BOEGER, M. R.; KOEHLER, H. S. Enraizamento de Sapium glandulatum (Vell.) Pax. pela aplicação de ácido indol butírico e ácido bórico. Leandra, Rio de Janeiro, v.16, p.11-16, 2001.

FERRI, C. P. Enraizamento de estacas de citrus. Revista Brasileira de Fruticultura, Cruz das Almas, v.19, n.1, p.113121, 1997.

FRENCH, C. J. Rooting of Rhododendron "Anna Rose Whitney" cittings as related to stem carbohydrate concentration. HortScience, Alexandria, v.25, n.4, p.409411, 1990 . 
HANSEN, O. B.; POTTER, J. R. Rooting of Apple, Rhododendron, and Mountain laurel cuttings from stock plants etiolated under two temperatures. HortScience, Alexandria, v.32, n.2, p. 304-306, 1997.

HARTMANN, H. T.; KESTER, D. E.; DAVIS JÚNIOR, F. T; GENEVE, R. L. Plant propagation: principles and practices. 7 ed. New York: Englewood Clipps, 2002.

HIGASHI, E. N.; SILVEIRA, R. L. V. A.; GONÇALVES, A. N. Propagação vegetativa de Eucalyptus: princípios básicos e a sua evolução no Brasil. Piracicaba: Instituto de Pesquisas e Estudos Florestais, 2000. (Circular técnica, n.192)

JANICK, J. A ciência da horticultura. Rio de Janeiro: F. Bastos, 1966.

LORENZI, H.; HERMES, M. S. Plantas ornamentais no Brasil: arbustivas, herbáceas e trapadeiras. 2.ed. Nova Odessa: Instituto Plantarum, 1999.

MARKS, T. R. Rhododendron cuttings. I. Improved rooting following "rejuvenation" in vitro. Journal of Horticultural Science, London, v.66, n.1, p.103-111. 1991.

NAKAMURA, M.; MATSUI, S.; HARADA, H. Effect of some methods and auxin treatmens on the rooting of stem cuttings taken from mature trees. Journal of the Japanese Society for Horticultural Science, Tokyo, v.47, n.2, p.227236. 1978.
PAES, E. G. B. Enraizamento de estacas de kiwizeiro com fitorreguladores nas quatro estações do ano. 2002. Dissertação (Mestrado em Agronomia - Produção Vegetal) - Universidade Federal do Paraná, Curitiba.

REIS, J. M. R; CHALFUN, N. N. J.; LIMA, L. C. O.; LIMA, L. C. Efeito do estiolamento e do ácido indol butírico no enraizamento de estacas do porta-enxerto Pyrus calleryana Dcne. Ciência Agrotécnica, Lavras, v.24, n.4, p.931-938, 2000.

RIBAS, K. C. Efeito de auxinas, ácido bórico e suas interações no enraizamento de estacas herbáceas de Macadamia integrifolia Maiden \& Betche. 1993. Dissertação (Mestrado em Ciências Biológicas - Botânica). Universidade Estadual Paulista, Botucatu.

STANKOVA, T.; PANETSOS, K. Vegetative propagation of Cupressus sempervirens L. of cretan origin by sofwood stem cuttins. Silvae Genética, Frankfurt, v.46, p.2-3, 1997.

WHITE, J.; LOVELL, P. H. The anatomy of root initiation in cuttings of Griselinia littoralis and Griselinia lúcida. Annals of Botany, London, v.54, p.7-20, 1984.

WILLIAMS, R. F.; BILDERBACK, T. E. Factors affeting rooting of Rhododendron maximum and Kalmia latifolia stem cuttings. HortScience, Alexandria, v.15, n.6, p.827828. 1980.

ZUFFELLATO-RIBAS, K. C.; RODRIGUES, J. D. Estaquia: uma abordagem dos principais aspectos fisiológicos. Curitiba: K. C. Zuffellato-Ribas, 2001. 